\title{
Myoelectric forearm prostheses: State of the art from a user-centered perspective
}

\author{
Bart Peerdeman, MSc; ${ }^{1-2}$ Daphne Boere, MSc; ${ }^{2-4}$ Heidi Witteveen, MSc; ${ }^{2,5}$ Rianne Huis in 't Veld, PhD; ${ }^{2-3}$ \\ Hermie Hermens, PhD; ${ }^{2-3,5}$ Stefano Stramigioli, PhD; ${ }^{1-2}$ Hans Rietman, MD, PhD; ${ }^{2-4}$ Peter Veltink, PhD; ${ }^{2,5}$ \\ Sarthak Misra, $\mathbf{P h D}^{\mathbf{1 - 2 *}}$ \\ ${ }^{1}$ Control Engineering, University of Twente, the Netherlands; ${ }^{2}$ MIRA-Institute for Biomedical Technology and Technical \\ Medicine, University of Twente, the Netherlands; ${ }^{3}$ Roessingh Research and Development, the Netherlands; ${ }^{4}$ Biomechanical \\ Engineering, University of Twente, the Netherlands; ${ }^{5}$ Biomedical Signals and Systems, University of Twente, the Netherlands
}

\begin{abstract}
User acceptance of myoelectric forearm prostheses is currently low. Awkward control, lack of feedback, and difficult training are cited as primary reasons. Recently, researchers have focused on exploiting the new possibilities offered by advancements in prosthetic technology. Alternatively, researchers could focus on prosthesis acceptance by developing functional requirements based on activities users are likely to perform. In this article, we describe the process of determining such requirements and then the application of these requirements to evaluating the state of the art in myoelectric forearm prosthesis research. As part of a needs assessment, a workshop was organized involving clinicians (representing end users), academics, and engineers. The resulting needs included an increased number of functions, lower reaction and execution times, and intuitiveness of both control and feedback systems. Reviewing the state of the art of research in the main prosthetic subsystems (electromyographic [EMG] sensing, control, and feedback) showed that modern research prototypes only partly fulfill the requirements. We found that focus should be on validating EMG-sensing results with patients, improving simultaneous control of wrist movements and grasps, deriving optimal parameters for force and position feedback, and taking into account the psychophysical aspects of feedback, such as intensity perception and spatial acuity.
\end{abstract}

Key words: amputee, control, EMG, feedback, forearm, hand, myoelectric, prosthetic, rehabilitation, sensing, user acceptance.

\section{INTRODUCTION}

The loss of a hand from amputation or congenital defects causes disability. Prostheses have been developed throughout history to restore some of the hand's original functionality and appearance. Though a variety of forearm prostheses are presently available, such as purely cosmetic hands and body-powered prostheses, modern prosthesis research is mainly focused on myoelectric (ME) prostheses [1]. A major problem for the development of new ME prostheses is that despite significant technological advancements, a large number of amputees choose not to use them [1]. The issues associated with acceptance of ME forearm prostheses have been investigated in the literature [1-3]. In these investigations, three main problems were mentioned as reasons that amputees stop using their ME prostheses: nonintuitive control, lack of sufficient

Abbreviations: DC $=$ direct current, EMG = electromyographic, $\mathrm{EPP}=$ extended physiological proprioception, $\mathrm{EPT}=$ extended physiological taction, $\mathrm{ME}=$ myoelectric.

*Address all correspondence to Sarthak Misra, PhD; Control Engineering, Carre 3609 CE-EWI, University of Twente, PO Box 217, Enschede 7500 AE, the Netherlands; +31-53489-2704; fax: +31-53-489-2223. Email: s.misra@utwente.nl DOI:10.1682/JRRD.2010.08.0161 
feedback, and insufficient functionality. However, these studies only considered prostheses that were commercially available at the time, and their information was mostly collected through questionnaires, which offer no opportunity for discussion or patient feedback.

Recent research projects have implemented new technologies in an attempt to overcome the shortcomings outlined by Atkins et al. and others [1-3]. However, the effect of these new technologies on user acceptance is currently unknown, because most of these systems are still in the prototype stage. Though several commercial ME forearm prostheses have recently been developed [46 ] that have greater functionality than those evaluated by Atkins et al. and others [1-3], their control systems do not yet take advantage of the recent improvements in sensing, control, and feedback research.

Klopsteg and Wilson recommend a user-centered approach for improving prosthesis performance and acceptance [7]. Therefore, we investigated the state of the art in ME forearm prosthesis research by determining a set of requirements for user acceptance and using these requirements to evaluate recent technological developments.

The structure of the prosthesis should result in intuitive control to improve user acceptance. This can be accomplished by making the signal flow between the prosthesis and the user resemble that of the nondisabled body. The signal flow can be divided into three parts: user intent, motion control, and sensory feedback. A prosthesis should contain subsystems that account for each of these parts; such a desired system is shown in Figure 1. The subsystems are described as follows: electromyographic (EMG) sensing, which determines user intent by detecting the activity of residual muscles through electrodes on the skin; control system, which actuates the prosthesis according to control signals received from EMG sensing; and feedback system, which provides the user with artificial sensory information. The combination of these three subsystems gives the user a noninvasive way to control an electronic prosthesis with the residual limb.

In the "Needs Assessment Method" section, we describe the process of assessing the needs for ME forearm prostheses. A workshop with participants from various relevant fields was arranged to establish these needs. We discuss the workshop results and formulate functional requirements for user acceptance in the section "Needs Assessment Results." In the "Literature Survey" section, we investigate the state of the art in ME prosthesis research
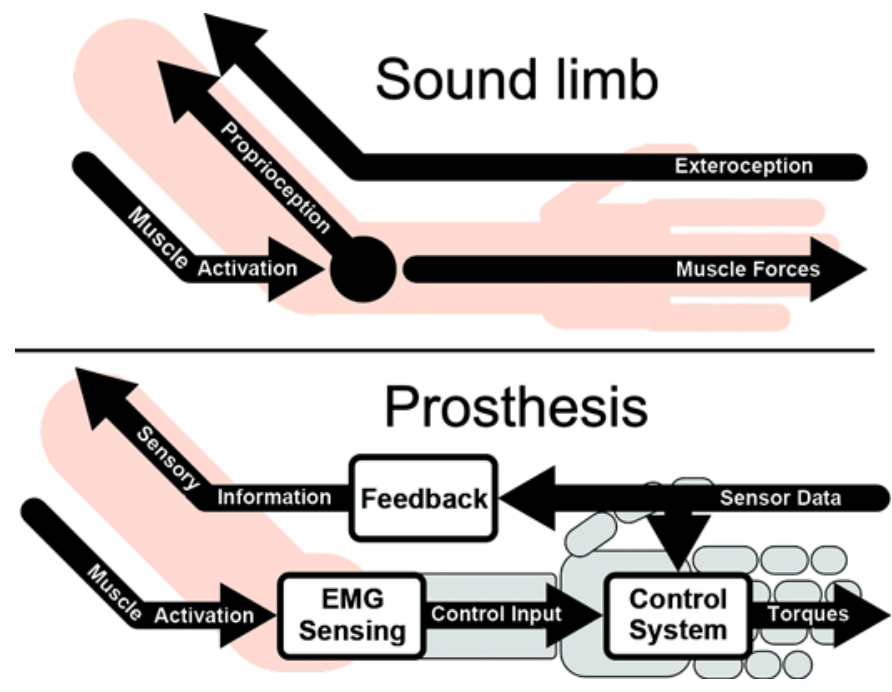

Figure 1.

Comparison of signal flow in sound human forearm and desired signal flow and main subsystems of modern myoelectric forearm prosthesis. EMG = electromyographic.

with a literature review covering the aforementioned requirements. In the "Discussion," we discuss the applicability of the needs assessment method. We then combine the results of the preceding two sections, evaluating the research state of the art using the functional requirements for user acceptance. Finally, we make recommendations for future research.

\section{NEEDS ASSESSMENT METHOD}

In this section, we describe the method used to determine user-centered needs. A workshop was organized in which the functional and nonfunctional needs of the ideal forearm prosthesis with regard to the EMG sensing, control, and feedback subsystems were discussed. Combining information from the literature [1-3] and the results of the workshop, we derived the functional requirements for ME forearm prostheses. The complete structure of the needs assessment used in this research is presented in a flow chart (Figure 2).

\section{Participants}

To develop a user-accepted ME forearm prosthesis, both users and technicians should be involved in the design process [7]. However, directly involving users in the design process may be difficult, because of differences 
in terminology and methodology [8]. In this case, representative users (i.e., clinicians with first-hand experience) can provide a useful alternative. As someone who has regular contact with many forearm prosthesis users, a representative user is highly familiar with the opinions and wishes of their patients. Therefore, the workshop participants comprised a multidisciplinary group (9 men and 10 women) of representative users and engineers from multiple centers throughout the Netherlands. All participants had interests and expertise in the area of upper-limb amputation and prostheses. The representative users were two occupational therapists, three rehabilitation medicine physicians, two physiotherapists, a certified prosthetist/orthotist, and a movement scientist. Six researchers and four engineers constituted the academic contributors.

\section{Orientation and Preparation}

Concrete representations of ME prosthesis use are necessary to facilitate good user-designer communication [9]. Therefore, activities of daily living that are relevant for forearm prosthesis users formed the starting point of the needs assessment. In preparation for the workshop, the participants were shown an educational video about different prosthetic options and user opinions. Important aspects

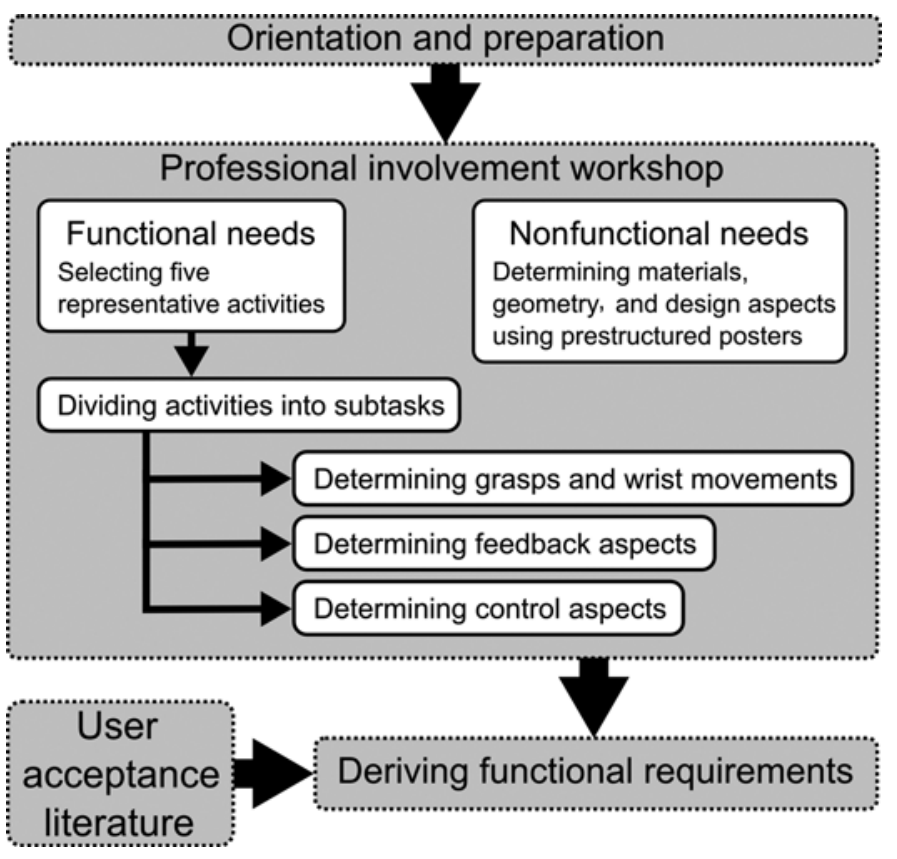

Figure 2.

Overview of needs assessment approach, including internal structure of workshop. of the daily use of forearm prostheses were investigated, in light of the first-hand knowledge of occupational therapists and physiotherapists (representing end users).

\section{Professional Involvement Workshop}

A plenary discussion led to a selection of five activities in which the important aspects of upper-limb prosthesis use are well represented. A refined version of the list of instrumental activities of daily living of Bookman et al., which was formed using these aspects as criteria, was used as a starting point [10]. Three different aspects of these activities were examined, focusing on the three prosthesis subsystems. Each activity was analyzed using a structured worksheet specially designed for this workshop (Figure 3). The worksheet contained a set of six predefined wrist movements and seven grasps.

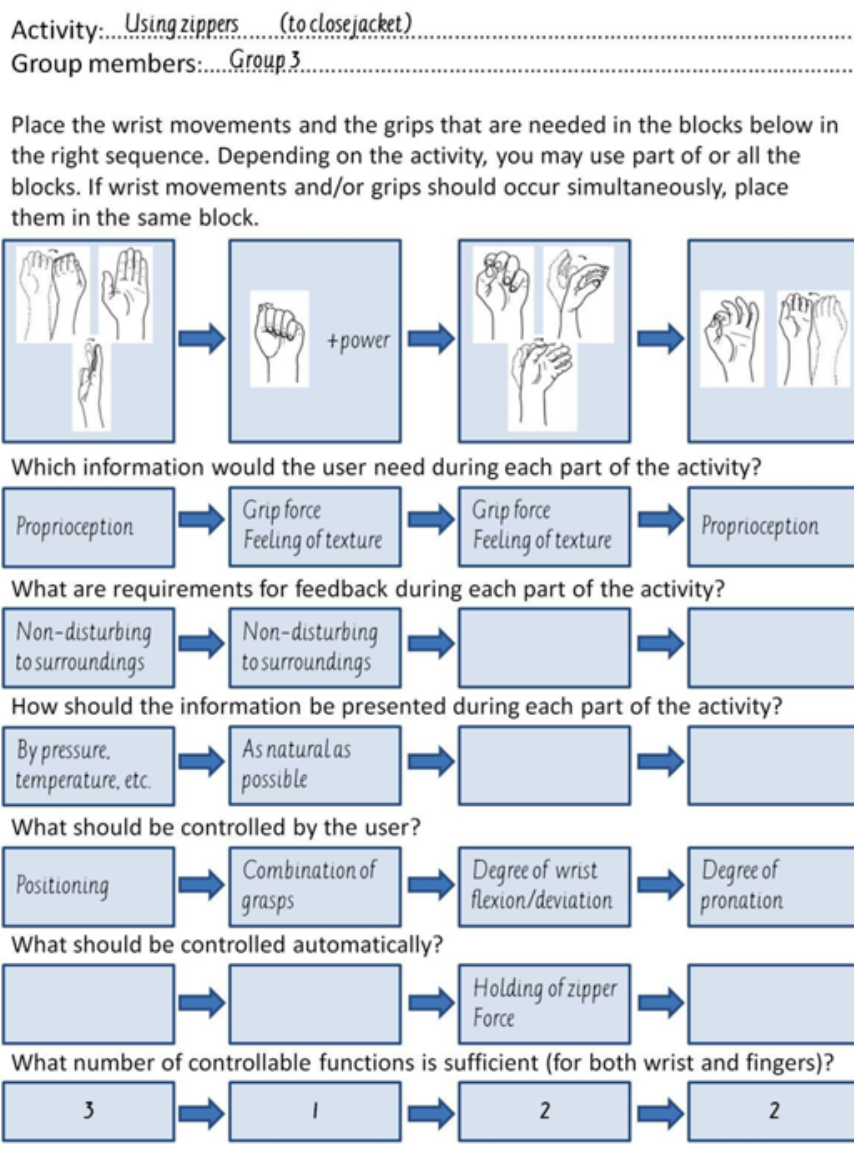

Figure 3.

Example of workshop activity sheet filled in by multidisciplinary group. Needs for using coat zippers are evaluated. Each column of blocks represents part of activity and is referred to as subtask. 
Multidisciplinary groups were each asked to divide one activity into subtasks. For every aspect, the worksheet contained several questions to be answered for each subtask of the activity (Figure 3). After the analyses in small groups, the needs for all aspects were validated and refined in a plenary discussion and consensus was reached.

\section{NEEDS ASSESSMENT RESULTS}

By combining the results of the workshop with the information obtained through the literature, we constructed a list of requirements for each of the prosthesis' subsystems. In this section, the needs as well as the resulting requirements derived from the workshop are described.

\section{Workshop Results}

In the workshop, the participants determined the specific needs associated with several activities of daily living. These activities, as mentioned in the "Needs Assessment Methods" section, were selected from a list of relevant activities to represent various aspects of prosthesis functionality, such as fine and gross motor control, speed, force, and coordination. The following activities were analyzed: using zippers, making a bed, grabbing a cup, catching a ball, and using a fork and knife.

\section{Grasps and Wrist Movements}

In general, the workshop participants considered grasps to be more important than wrist movements in executing the tasks. The main grasp types selected in the plenary discussion were the lateral, cylindrical, and tripod grasps (Figure 4). Additionally, the index finger point was mentioned as an important gesture for various other activities (e.g., typing). Of the wrist movements, rotation and flexion/ extension were considered equally useful when used to perform a natural grasping maneuver in combination with a grasp. These wrist movements would also avoid awkward elbow and shoulder motions.

\section{Control}

The main focus of the discussion on prosthesis control was on selecting the functions that the prosthesis should automatically control. Generally, the initiation of actions was considered to be best controlled by the user, whereas the actual execution of those actions can be performed automatically. Grasp selection, wrist movement control, and initiation of grasp execution were mentioned as decisions that the user should control.

The participants felt the prosthesis should automatically continue holding an object once grasped. This allows the user to focus on moving the object with arm and wrist movements. During such an action, slipping of the object should be prevented.

It was considered desirable to have wrist movements under direct user control. Performing two wrist movements simultaneously was also considered desirable, but it could require a more automated execution of these movements. Direct user control of the speed of grasping or the force applied to a grasped object were found useful in several

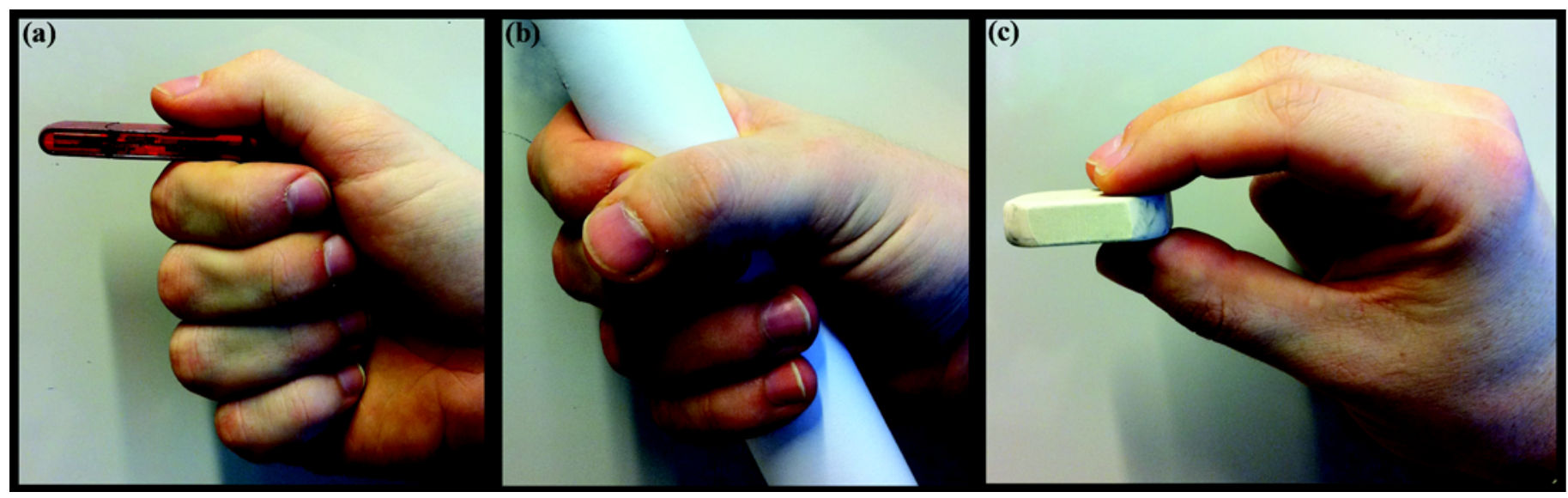

Figure 4.

Three main grasp types selected during workshop: (a) lateral, (b) cylindrical, and (c) tripod. 
activities and could be implemented as an optional alternative to automatic grasping and holding.

\section{Feedback}

For each activity, both the type of information to be fed-back and the method of feedback were considered. Workshop participants stated that force was the most important type of information for feedback, because it is impossible to determine through visual inspection. Applying the right amount of force is essential when handling fragile objects or interacting with humans and animals. Feedback on the position of the fingers was considered important to reduce the attention required and allow for more intuitive grasping. A combination of both force and position information could provide the user with a measure of object stiffness. Feedback was also mentioned as being useful for indicating control system status, such as when grasp closure has been completed.

The discussion on feedback methods revolved mostly around the choice between continuous and discrete feedback. Although continuous feedback can improve the user's ability to handle the prosthesis intuitively, the user's perception of a nonphysiological signal may fade over time. In contrast, discrete feedback should not be so abrupt that it disturbs the user. This type of feedback could be useful for indicating control system status but was considered less important than continuous feedback.
Feedback was only considered of added value when intuitive and simple. Other mentioned requirements for feedback were for it to be unobtrusive to others and comfortable to the user. The ability to adjust feedback for individual patients was also considered essential.

\section{Requirements}

In this section, a list of functional requirements based on the workshop results and the literature $[1-3,11]$ is presented. During the plenary discussion at the end of the workshop, the functional requirements were determined based on the results of analyzing the activities, as shown in Figure 2. In Table 1, these requirements are listed for each subsystem in no particular order.

\section{LITERATURE SURVEY}

In this section, the state of the art of recent ME forearm prosthesis research is described with regard to each of the requirements in Table 1, separated by subsystem.

\section{EMG Sensing}

The sensing part of ME prostheses is based on EMG signals. These signals are the electrical expression of the neuromuscular activation generated by skeletal muscles [12-14] and contain rich information regarding the

\section{Table 1.}

Functional requirements for user acceptance of myoelectric forearm prostheses, sorted by subsystem. These requirements were obtained through combination of needs assessment workshop and literature review.

\begin{tabular}{lcl}
\hline Subsystem & Number & \multicolumn{1}{c}{ Requirement } \\
\hline EMG Sensing & 1 & Multiple wrist movements and grasp types should be easily selectable. \\
& 2 & Time delay should be short enough to not disturb user. \\
Control & 3 & User should be able to indicate desired speed of wrist movements and force of grasps. \\
& 4 & Wrist movement and grasp type should be simultaneously distinguishable. \\
& 1 & Available grasp types: cylindrical grasp, tripod grasp, lateral grasp. \\
& 3 & Available wrist movements: flexion/extension and rotation. \\
& 4 & Prosthesis should automatically continue holding an object once grasped. \\
Feedback & 5 & Prosthesis should automatically prevent slipping of any held objects. \\
& 6 & User should be able to directly control speed of wrist movements and force of grasps. \\
& 1 & Continuous and proportional feedback on grasping force should be provided. \\
& 3 & Position feedback should be provided to user. \\
\hline EMG = electromyographic. & & Interpretation of stimulation used for feedback should be easy and intuitive. \\
\hline \hline
\end{tabular}


motion intended by the user. In modern prosthesis research, EMG is used for pattern-recognition-based ME control systems. The sensing principle for every system is basically the same (Figure 5) [15-18].

Of the functional requirements list that resulted from the workshop (Table 1), four requirements fall into the sensing category. In this section, the current state of the art of EMG sensing is evaluated with respect to how these requirements are addressed and what results are achieved. Table 2 provides an overview of sensing systems for ME forearm prostheses; it will be used to represent the current state of the art of EMG sensing systems research.

\section{Sensing Requirement 1: Multiple Selectable Wrist Movements and Grasps}

Over the last 20 years, the focus of the literature has been on increasing the number of prosthesis functions that can be controlled, since this is the biggest drawback of commercially available forearm prostheses [1-2,17,19]. In principle, the number of controllable functions can be increased by using pattern recognition. Among many other features, amplitude features (mean absolute value and root-mean-square value) are often used to distinguish different contraction patterns (ranging from 4 to 8) and high accuracies (between 92\% and 99\%) can be achieved with them [20-24]. Examples of frequently used classifiers in the literature are linear discriminant analysis [22,25-28] and artificial neural networks [29-31]. The highest achieved accuracies for both classifiers were around 98 percent. Most classification results in Table 2 were

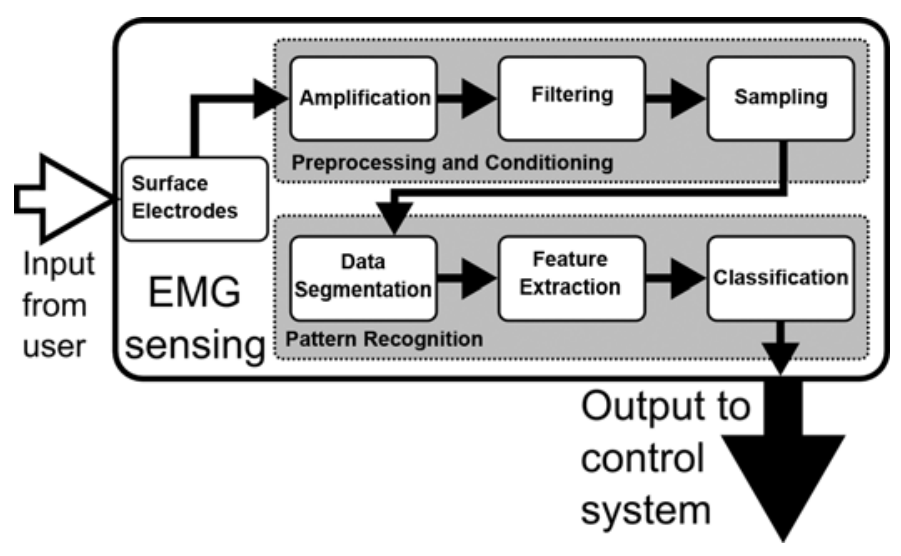

Figure 5.

Electromyographic sensing subsystems describing signal flow from detection of muscle contraction to feature extraction and classification. Adapted from Asghari Oskoei M, Hu H. Myoelectric control systemsA survey. Biomed Signal Process Control. 2007;2(4):275-94. achieved with nondisabled subjects. A limited number of results can be found for transradial amputee patients [17,32-34].

Concerning the type of classes that are included in the studies, most research only investigates forearm and wrist movement contractions. For a higher than 4-class problem, opening and closing of the hand is often included. Studies by Tenore et al. [35] and Sebelius et al. [21,29] incorporated flexion and extension of the separate fingers and thumb in classification. In recent studies, more focus is found on functional grasps, such as the cylindrical, tripod, and lateral grasps [28,36-38].

To enable easily selectable prosthesis functions, Ajiboye and Weir state that a balance must be found between choosing sites at which the user can easily contract his/her muscles and choosing sites that are most naturally mapped to the appropriate function of the prosthesis (direct mapping) [20]. Both Shenoy et al. [24] and Tenore et al. [35] emphasized that with direct mapping, a more natural and intuitive control strategy can be achieved.

\section{Sensing Requirement 2: Nondisturbing Time Delay}

Short observation windows are required to ensure that the user's perceived delay is not considered disturbing. Here, this perceived time delay is defined as the time from user input to initiation of the intended motion and consists of the calculation times of all elements depicted in Figure 5. Yet, a trade-off exists in response time and accuracy, since an analysis window should be long enough to reliably estimate features [19]. In 1993, Hudgins et al. stated that the window for analysis plus the processing time should be equal to or less than $300 \mathrm{~ms}$, otherwise the perceived time delay will become unacceptable for the user [17]. Although this limit has been generally accepted and implemented in studies of the last 20 years, relatively little work has been performed on the objective examination of the effect of controller delays on prosthesis performance [39].

Recently, Farrell and Weir readdressed the subject of optimal time delay [39]. By testing prostheses with nondisabled subjects, they found the optimal delay lies within the 100 to $125 \mathrm{~ms}$ range. This research raised discussions as to whether it would be desirable to use shorter windows to create a more usable prosthesis, even though this would cause lower control accuracy. Hargrove et al. state that users would prefer more controllable functions and a slower system over less functions and a faster system [40]. Nevertheless, researchers try to incorporate the new 
Table 2.

Electromyographic sensing systems.

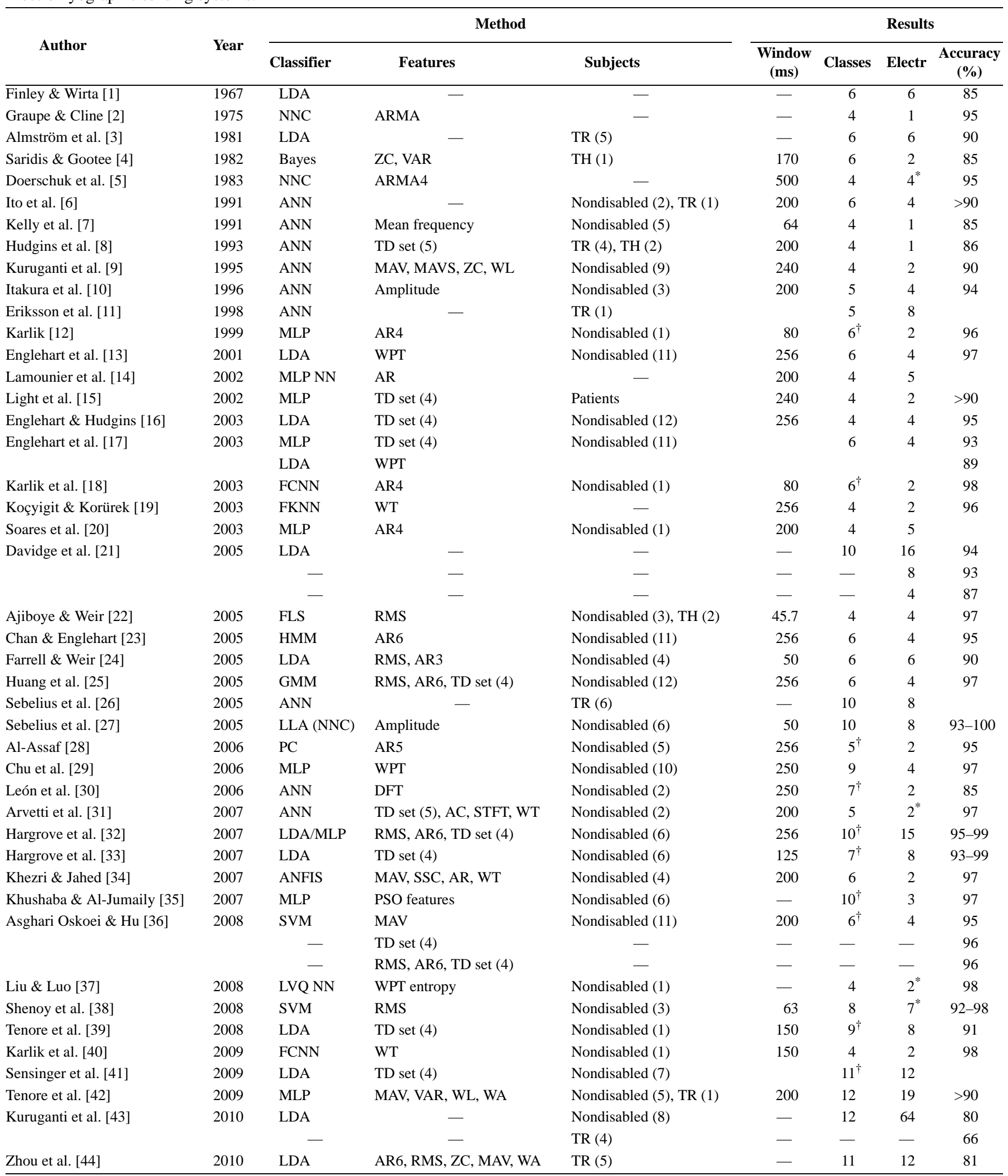


JRRD, Volume 48, Number 6, 2011

Table 2. (cont)

Electromyographic sensing systems.

*Denotes monopolar.

${ }^{\dagger}$ Denotes rest included.

1. Finley FR, Wirta RW. Myocoder studies of multiple myopotential response. Arch Phys Med Rehabil. 1967;48(11):598-601. [PMID: 6060789]

2. Graupe D, Cline WK. Functional separation of EMG signals via ARMA identification methods for prosthesis control purposes. IEEE Trans Syst Man Cybernetics. 1975;5(2):252-59.

3. Almström C, Herberts P, Körner L. Experience with Swedish multifunctional prosthetic hands controlled by pattern recognition of multiple myoelectric signals. Int Orthop. 1981;5(1):15-21. [PMID: 7275404]

4. Saridis GN, Gootee TP. EMG pattern analysis and classification for a prosthetic arm. IEEE Trans Biomed Eng. 1982;29(6):403-12. [PMID: 7106790] DOI:10.1109/TBME.1982.324954

5. Doerschuk PC, Gustafson DE, Willsky AS. Upper extremity limb function discrimination using EMG signal analysis. IEEE Trans Biomed Eng. 1983;30(1):18-29. [PMID: 6826182] DOI:10.1109/TBME.1983.325162

6. Ito K, Tsuji T, Kato A, Ito M. Limb-function discrimination using EMG signals by neural network and application to prosthetic forearm control. Proceedings of the IEEE International Joint Conference on Neural Networks; 1991 Nov 18-21; Singapore. Los Alamitos (CA): IEEE; 1991. p. 1214-19. DOI:10.1109/IJCNN.1991.170562

7. Kelly MF, Parker PA, Scott RN. Neural network classification of myoelectric signal for prosthesis control. J Electromyogr Kinesiol. 1991;1(4):229-36. [PMID: 20870513] DOI:10.1016/1050-6411(91)90009-T

8. Hudgins B, Parker P, Scott RN. A new strategy for multifunction myoelectric control. IEEE Trans Biomed Eng. 1993;40(1):82-94. [PMID: 8468080] DOI:10.1109/10.204774

9. Kuruganti U, Hudgins B, Scott RN. Two-channel enhancement of a multifunction control system. IEEE Trans Biomed Eng. 1995;42(1):109-11. [PMID: 7851924] DOI:10.1109/10.362912

10. Itakura N, Kinbara Y, Fuwa T, Sakamoto K. Discrimination of forearm’s motions by surface EMG signals using neural network. Appl Human Sci. 1996; 15(6):287-94. [PMID: 9008983] DOI:10.2114/jpa.15.287

11. Eriksson L, Sebelius F, Balkenius C. Neural control of a virtual prosthesis. Proceedings of the International Conference on Artificial Neural Networks (ICANN); 1998; Skövde, Sweden. p. 905-10.

12. Karlik B. Differentiating type of muscle movement via AR modeling and neural network classification. Turk J Elec Eng. 1999;7(1):45-52.

13. Englehart K, Hudgins B, Parker PA. A wavelet-based continuous classification scheme for multifunction myoelectric control. IEEE Trans Biomed Eng. 2001; 48(3):302-11. [PMID: 11327498]

DOI:10.1109/10.914793

14. Lamounier E, Soares A, Andrade A, Carrijo R. A virtual prosthesis control based on neural networks for EMG pattern classification. Proceedings of Artificial Intelligence and Soft Computing (ASC); 2002 Jul 17-19; Banff, Canada. p. 1-9.

15. Light CM, Chappell PH, Hudgins B, Engelhart K. Intelligent multifunction myoelectric control of hand prosthesis. J Med Eng Technol. 2002;26(4):139-46. [PMID: 12396328$]$ DOI:10.1080/03091900210142459

16. Englehart K, Hudgins B. A robust, real-time control scheme for multifunction myoelectric control. IEEE Trans Biomed Eng. 2003;50(7):848-54. [PMID: 12848352] DOI:10.1109/TBME.2003.813539

17. Englehart K, Hudgins B, Chan AD. Continuous multifunction myoelectric control using pattern recognition. Technol Disabil. 2003;15(2):95-103.

18. Karlik B, Tokhi MO, Alci M. A fuzzy clustering neural network architecture for multifunction upper-limb prosthesis. IEEE Trans Biomed Eng. 2003;50(11): 1255-61. [PMID: 14619995] DOI:10.1109/TBME.2003.818469

19. Koçyigit Y, Korürek M. EMG signal classification using wavelet transform and fuzzy clustering algorithms. Proceedings of the International Conference on Electrical and Electronics Engineering (ELECO); 2003; Bursa, Turkey.

20. Soares A, Andrade A, Lamounier E, Carrijo R. The development of a virtual myoelectric prosthesis controlled by an EMG pattern recognition system based on neural networks. J Intelligent Inform Syst. 2003;21(2):127-41. DOI:10.1023/A:1024758415877

21. Davidge K, Englehart K, Parker PA. Multifunction myoelectric control of prostheses using a linear electrode array. Proceedings of the 19th Congress of the International Society of Electrophysiological Kinesiology; 2005 Jun; Boston, MA. p. 59-65.

22. Ajiboye AB, Weir RF. A heuristic fuzzy logic approach to EMG pattern recognition for multifunctional prosthesis control. IEEE Trans Neural Syst Rehabil Eng. 2005;13(3):280-91. [PMID: 16200752]

DOI:10.1109/TNSRE.2005.847357

23. Chan AD, Englehart KB. Continuous myoelectric control for powered prostheses using hidden Markov models. IEEE Trans Biomed Eng. 2005;52(1):121-24. [PMID: 15651571] DOI:10.1109/TBME.2004.836492

24. Farrell TR, Weir RF. Pilot comparison of surface vs. implanted EMG for multifunctional prosthesis control. In: Proceedings of the IEEE 9th International Conference on Rehabilitation Robotics (ICORR); 2005 Jun 28-Jul 1; Chicago, IL. Los Alamitos (CA): IEEE; 2005. p. 277-80. DOI:10.1109/ICORR.2005.1501101

25. Huang Y, Englehart KB, Hudgins B, Chan AD. A Gaussian mixture model based classification scheme for myoelectric control of powered upper limb prostheses. IEEE Trans Biomed Eng. 2005;52(11):1801-11. [PMID: 16285383] DOI:10.1109/TBME.2005.856295

26. Sebelius FC, Rosén BN, Lundborg GN. Refined myoelectric control in below-elbow amputees using artificial neural networks and a data glove. J Hand Surg Am. 2005;30(4):780-89. [PMID: 16039372] DOI:10.1016/j.jhsa.2005.01.002 
Table 2. (cont)

Electromyographic sensing systems.

27. Sebelius F, Axelsson M, Danielsen N, Schouenborg J, Laurell T. Real-time control of a virtual hand. Technol Disabil. 2005;17(3):131-41.

28. Al-Assaf Y. Surface myoelectric signal analysis: Dynamic approaches for change detection and classification. IEEE Trans Biomed Eng. 2006;53(11):2248-56. [PMID: 17073330] DOI:10.1109/TBME.2006.883628

29. Chu JU, Moon I, Mun MS. A real-time EMG pattern recognition system based on linear-nonlinear feature projection for a multifunction myoelectric hand. IEEE Trans Biomed Eng. 2006;53(11):2232-39. [PMID: 17073328] DOI:10.1109/TBME.2006.883695

30. León M, Leija L, Munoz R. System for the identification of multiple movements of the hand. Proceedings of the 3rd International Conference on Electrical and Electronics Engineering; 2006 Sep 6-8; Veracruz, Mexico. Los Alamitos (CA): IEEE; 2006. p. 1-3.

31. Arvetti M, Gini G, Folgheraiter M. Classification of EMG signals through wavelet analysis and neural networks for controlling an active hand prosthesis. Proceedings of the IEEE 10th International Conference on Rehabilitation Robotics; 2007 Jun 13-15; Noordwijk, the Netherlands. Los Alamitos (CA): IEEE; 2007. p. 531-36. DOI:10.1109/ICORR.2007.4428476

32. Hargrove LJ, Englehart K, Hudgins B. A comparison of surface and intramuscular myoelectric signal classification. IEEE Trans Biomed Eng. 2007;54(5):847-53. [PMID: 17518281] DOI:10.1109/TBME.2006.889192

33. Hargrove LJ, Losier Y, Lock B, Englehart K, Hudgins B. A real-time pattern recognition based myoelectric control usability study implemented in a virtual environment. Conf Proc IEEE Eng Med Biol Soc. 2007;2007:4842-45. [PMID: 18003090]

34. Khezri M, Jahed M. Real-time intelligent pattern recognition algorithm for surface EMG signals. Biomed Eng Online. 2007;6:45. [PMID: 18053184] DOI:10.1186/1475-925X-6-45

35. Khushaba RN, Al-Jumaily A. Channel and feature selection in multifunction myoelectric control. Conf Proc IEEE Eng Med Biol Soc. 2007;2007:5182-25. [PMID: 18003175]

36. Asghari Oskoei M, Hu H. Evaluation of support vector machines in upper limb motion classification using myoelectric signal. Proceedings of the Iranian Conference on Biomedical Engineering; 2008; Shahed University, Iran. p. 176-80.

37. Liu Z, Luo Z. Hand motion pattern classifier based on EMG using wavelet packet transform and LVQ neural networks. Proceedings of IEEE International Symposium on IT in Medicine and Education; 2008 Dec 12-14; Xiamen, China. Los Alamitos (CA): IEEE; 2008. p. $28-32$.

38. Shenoy P, Miller KJ, Crawford B, Rao RN. Online electromyographic control of a robotic prosthesis. IEEE Trans Biomed Eng. 2008;55(3):1128-35. [PMID: 18334405] DOI:10.1109/TBME.2007.909536

39. Tenore F, Armiger RS, Vogelstein RJ, Wenstrand DS, Harshbarger SD, Englehart K. An embedded controller for a 7-degree of freedom prosthetic arm. Conf Proc IEEE Eng Med Biol Soc. 2008;2008:185-88. [PMID: 19162624]

40. Karlik B, Koçyigit Y, Korürek M. Differentiating types of muscle movements using a wavelet based fuzzy clustering neural network. Expert Systems. 2009;26(1):49-59. DOI:10.1111/j.1468-0394.2008.00496.X

41. Sensinger JW, Lock BA, Kuiken TA. Adaptive pattern recognition of myoelectric signals: Exploration of conceptual framework and practical algorithms. IEEE Trans Neural Syst Rehabil Eng. 2009;17(3):270-78. [PMID: 19497834] DOI:10.1109/TNSRE.2009.2023282

42. Tenore FV, Ramos A, Fahmy A, Acharya S, Etienne-Cummings R, Thakor NV. Decoding of individuated finger movements using surface electromyography. IEEE Trans Biomed Eng. 2009;56(5):1427-34. [PMID: 19473933] DOI:10.1109/TBME.2008.2005485

43. Kuruganti U, Daley H, Englehart KB. High density EMG data of normally limbed and transradial amputees. Proceedings of the Congress of the International Society of Electrophysiology and Kinesiology (ISEK); 2010 Jun 16-19; Aalborg, Denmark.

44. Zhou R, Liu X, Li G. Myoelectric signal feature performance in classifying motion classes in transradial amputees. Proceedings of the Congress of the International Society of Electrophysiology and Kinesiology (ISEK). 2010 Jun 16-19; Aalborg, Denmark.

AC $=$ autocorrelation coefficients, Accuracy = percentage of correctly classified muscle-activation patterns, ANFIS = adaptive neurofuzzy inference system, ANN = artificial neural network, AR\# = autoregressive model (\#th order), ARMA\# = autoregressive-moving-average model (\#th order), DFT = discrete Fourier transform, Electr $=$ number of electrodes, FCNN = fuzzy clustering neural network, FKNN = fuzzy $k$-nearest neighbor classifier, FLS = fuzzy logic system, GMM = Gaussian mixture model, HMM = hidden Markov model, LDA = linear discriminant analysis, LLA = lazy learning algorithm, LVQ NN = learning vector quantization neural network, MAV = moving average, MAVS = moving average slope, $\mathrm{MLP}=$ multilayer perceptron, $\mathrm{NN}=$ neural network, NNC $=$ nearest neighbor classifier, $\mathrm{PC}=$ polynomial classifier, PSO = particle swarm optimization, RMS = root-mean-square, SSC = slope sign changes, STFT = short-time Fourier transform, SVM = support vector mechanism, TD = time domain [set(4): MAV, ZC, SSC, WL; set(5): MAV, ZC, SSC, WL, MAVS], TH = transhumeral amputee, TR = transradial amputee, $\mathrm{VAR}=$ variance, $\mathrm{WA}=$ Willison amplitude, $\mathrm{WL}=$ wavelength, $\mathrm{WPT}=$ wavelet packet transform, $\mathrm{WT}=$ wavelet transform, $\mathrm{ZC}=$ zero crossings.

recommendation of Farrell and Weir, as can be found in Hargrove et al. and others [40-43].

\section{Sensing Requirement 3: Proportional Control of Force and Speed}

A natural and intuitive control strategy would reflect the original neuromuscular system, which is capable of proportionally and simultaneously controlling multiple functions. The amplitude of the EMG signal caused by isometric steady-state contraction of an individual muscle is proportional to the force produced by the muscle $[24,44-$ 45]. However, few studies include so-called proportional control in pattern-recognition systems; this could be due to the larger challenge of deriving the contraction speed or 
force per class in a multiclass problem [40]. Hargrove et al. computed a linear combination of root-mean-square values over all channels and normalized them by a "motion specific factor" derived from training data [46]. Jiang et al. and others recently included proportional control in the experimental setup [47-49]. By using a standard time domain feature set, they were able to capture more than 80 percent of the measured force variability of three simultaneously activated wrist movements.

\section{Sensing Requirement 4: Simultaneous Control of Wrist Movements and Grasps}

As opposed to the previous requirements, simultaneous control of wrist movements and grasps is rarely addressed in the EMG literature. While this was mentioned as being performed during testing of the SVEN Hand [50], no qualitative results were found. As mentioned previously, simultaneous control of two or three contraction patterns at once has been explored by Jiang et al. and others [47-49]. However, their focus was on proportional control, and therefore, no explicit results on simultaneous control were reported.

\section{Control}

Control systems for ME prostheses combine the output signals of the EMG sensing system with data from internal and external sensors to generate the motions intended by the user. These systems can be broken down into two parts: first, the high-level control system that interprets the classified EMG signals to produce desired angles for each joint; second, the low-level control system that takes the high-level system's set points and controls the individual joints to the proper angles. The low-level control systems [51] are less important in establishing user control of the prosthesis' functions and as such are not covered in detail in this article.

The various prosthesis control systems that have been evaluated are listed in Table 3 . Though not intended to be comprehensive, this list of systems has been chosen to represent the state of the art in prosthesis control research and to cover various different approaches.

\section{Control Requirement 1: Available Grasp Types}

The reviewed systems feature two main methods of grasp control: either a selection of discrete grasp types or direct user finger control (Table 3). With the first approach, used by the MANUS hand [52], Fluidhand [53], and Southampton hybrid [54] systems, the user chooses from a set list of grasps. This approach can allow the specific grasp types available to be customized to the user's preference during training [52].

The second approach is used in the AR III Hand system [55] and one of the Cyberhand control systems [56]. Although direct finger control can be considered more natural than the grasp selection approach, it could be more difficult for the user to get the fingers in the right position for the task given the limited amount of control inputs available.

The second Cyberhand control system [57] was used to test both a selection of two or three discretely selectable grasps and direct control of the thumb opposition angle. Users had difficulty taking advantage of direct thumb control and often disregarded it entirely.

\section{Control Requirement 2: Wrist Movement}

Currently, only a few prosthesis prototypes feature user-controlled wrist movement, so few of the control systems support it. One example of both rotation and flexion/extension has been found in the SVEN Hand [50]. The MANUS hand [58] and Southampton [54] control systems enable control of wrist rotation only. With the latter two systems, wrist movement control is implemented in the same way as grasp selection, which makes simultaneous grasping and wrist movement impossible.

\section{Control Requirements 3 and 4: Automatic Holding and Slip Prevention}

The MANUS hand [52] and Fluidhand [53] systems will both continue to hold a grasped object unless given another signal. The Southampton system [54] automatically holds objects as well, but also prevents slipping of objects, which is detected by way of acoustic sensors. While the Cyberhand contains the force sensors needed for slip prevention, it currently does not have a response time short enough to use it [59].

\section{Control Requirement 5: Grasp Execution Time}

For the control system's reaction time, the most important factor is the number of control signals a user needs to provide to activate a certain action. This number varies from hand to hand. For example, the MANUS hand system [52] always requires a three-symbol code to execute any command. In contrast, the Southampton hand system [54] requires a single close signal to perform a simple grasp; however, an additional control signal is 
Table 3.

EMG-based prosthetic hand systems. M1-3 designate three different control systems evaluated by Cipriani et al. [1].

\begin{tabular}{|c|c|c|c|c|c|c|c|c|}
\hline \multirow{2}{*}{ Authors } & \multirow{2}{*}{ Year } & \multirow{2}{*}{ Prototype Name } & \multicolumn{4}{|c|}{ Grasp Control } & \multirow{2}{*}{ Wrist Control } & \multirow{2}{*}{$\begin{array}{l}\text { Force/Speed } \\
\text { User Control }\end{array}$} \\
\hline & & & Available Types & Selection Method & Execution & Time* $^{*}$ & & \\
\hline Pons et al. [2] & 2005 & MANUS Hand & Customizable & EMG code & Automatic & 1.0 & Rotation & Force \\
\hline Yang et al. [3] & 2009 & AR III Hand & N/A & Finger control $^{\dagger}$ & By user & 0.5 & None & Neither \\
\hline Herberts et al. [5] & 1973 & SVEN Hand & N/A & EMG classification & By user & 2.0 & Rotation, F/E & None \\
\hline Light et al. [6] & 2002 & Southampton Hand & Customizable & EMG classification & By user & 2.5 & Rotation & Force \\
\hline \multirow[t]{3}{*}{ Cipriani et al. [1] } & 2008 & Cyberhand (M1) & Lateral, cylindrical & EMG code & Automatic & 1.0 & None & Neither \\
\hline & & Cyberhand (M2) & Lateral, cylindrical & EMG code & Automatic & 1.0 & None & Force \\
\hline & & Cyberhand (M3) & N/A & Finger control $^{\dagger}$ & By user & 1.0 & None & Force \\
\hline
\end{tabular}

*Approximate time needed to close grasp (in seconds).

${ }^{\dagger}$ Direct finger control replaces separate grasp selection method.

1. Cipriani C, Zaccone F, Micera S, Carrozza MC. On the shared control of an EMG-controlled prosthetic hand: Analysis of user-prosthesis interaction. IEEE Trans Robotics. 2008;24(1):170-84. DOI:10.1109/TRO.2007.910708

2. Pons JL, Ceres R, Rocon E, Levin S, Markovitz I, Saro B, Reynaerts D, Van Moorleghem W, Bueno L. Virtual reality training and EMG control of the MANUS hand prosthesis. Robotica. 2005;23(3):311-17. DOI:10.1017/S026357470400133X

3. Yang DP, Zhao JD, Gu YK, Wang XQ, Li N, Jiang L, Liu H, Huang H, Zhao DW. An anthropomorphic robot hand developed based on underactuated mechanism and controlled by EMG signals. J Bionic Eng. 2009;6(3):255-63. DOI:10.1016/S1672-6529(08)60119-5

4. Schulz S, Pylatiuk C, Reischl M, Martin J, Mikut R, Bretthauer G. A hydraulically driven multifunctional prosthetic hand. Robotica. 2005;23(3):293-99. DOI:10.1017/S0263574704001316

5. Herberts P, Almström C, Kadefors R, Lawrence PD. Hand prosthesis control via myoelectric patterns. Acta Orthop Scand. 1973;44(4):389-409. [PMID: 4771275]

6. Light CM, Chappell PH, Hudgins B, Engelhart K. Intelligent multifunction myoelectric control of hand prosthesis. J Med Eng Technol. 2002;26(4):139-46. [PMID: 12396328$]$ DOI:10.1080/03091900210142459

7. Matrone G, Cipriani C, Secco EL, Carrozza MC, Magenes G. Bio-inspired controller for a dexterous prosthetic hand based on principal components analysis. Conf Proc IEEE Eng Med Biol Soc. 2009;2009:5022-25. [PMID: 19964659]

EMG = electromyographic, F/E = flexion/extension, N/A = not applicable.

required to increase the applied force, which causes some delay in its execution.

Once grasp execution has started, the grasping speed depends mainly on the type of actuators used. All hands in Table 3 except the Fluidhand [53] use direct current (DC) motor actuators, which require a transmission with high gear ratio to produce the required torque. This reduces the motor's speed significantly.

\section{Control Requirement 6: User-Controlled Force and Speed}

Two main methods of force control implementation are commonly used. The first gives the user direct control over the force with which the grasp is closed and with which objects are held and is used by the Cyberhand and MANUS hand [52,57]. The second method automatically applies sufficient force but gives the user the option of switching to direct force control during grasping; the Southampton control system [54] features this option.

Speed control is relatively rare among the reviewed control systems, only being supported by the Fluidhand [53]. This is because of the low priority of speed versus force control, which is performed through a similar channel. It should be noted that various modern prosthesis prototypes have grasp closing times on the order of $1 \mathrm{~s}$ (Table 3), which would diminish the effect of speed control.

\section{Feedback}

For the majority of forearm prosthesis research, force and position information is only directed to the prosthesis itself (e.g., in automated slip control) [54-55], but some efforts have been made to provide feedback to the user. A natural way to close the prosthesis control loop that also incorporates feedback is the use of extended physiological proprioception (EPP) as proposed by Simpson [60]. However, the focus of this article is on ME prostheses, and therefore, feedback applications of the EPP principle are not considered here.

Examples of artificial feedback through nerve stimulation or haptic feedback can be found, but the focus in research is on vibrotactile and electrotactile stimulation because of their unobtrusive nature, easy applicability in prostheses, and comfort for the user. In this section, the 
state of the art research on feedback is evaluated according to the requirements found in Table 1.

\section{Feedback Requirement 1: Force Feedback}

The most natural way to directly close the loop between sensing and feedback would be the direct stimulation of the afferent nerves, which is being investigated in several studies [61-63]. To avoid the invasive character of this solution, but still provide feedback by the same modality, many researchers use extended physiological taction (EPT), in which force measured by force sensors is transmitted to the user via force applied to the skin with the same amplitude and modality [64-66].

Early applications of force feedback have mainly used electrotactile stimulation. Force levels were modulated either by amplitude-following a linear [67] or nonlinear relation [68] —or by pulse rate [69-72]. Effects of feedback were mainly subjectively evaluated and showed positive results [67,69-71]. The rare quantitative analyses showed increased performance in grasping tasks [68,72]. However, electrotactile stimulation has several potential disadvantages, the most significant of which is the likelihood of painful stimulations. Since there have been several advancements in vibrotactile stimulation (e.g., the miniaturization of the stimulators), most recent research projects have abandoned electrotactile stimulation in favor of vibrotactile stimulation.

Force feedback systems using vibrotactile stimulation have been incorporated in the hands of three projects mentioned previously: the MANUS hand [52], Cyberhand [57], and Fluidhand [73]. Subjective evaluation through questionnaires showed positive experiences in comfort and utility [57], but feedback became disturbing when applied continuously [74]. Evaluation of grasping performances showed a 15 to 77 percent decrease in applied grasping forces [74], but no significant differences in performance were noted when compared with the nonfeedback situation [57].

\section{Feedback Requirement 2: Position Feedback}

In comparison to the application of force feedback, feedback of position is even more rarely described; only two applications of tactile position feedback in arm prosthesis prototypes were found. The first approach, for the Utah arm [75-76], is a combination of feedback of grasp force (via varying electrotactile pulse width) and level of hand opening (by pulse rate modulation) by a single electrode. Evaluation showed that it was not possible to pro- vide force and position feedback using the same electrode, but performance in distinguishing object sizes does increase with feedback. The second approach uses the phantom sensation phenomenon [77], in which sensations are felt in between two simultaneously activated stimulators with different intensities. Feedback of the level of flexion and extension of the elbow was provided by this method. The performance of the subjects in matching and reaching tasks was considerably improved and comparable to performance with a body-powered prosthesis.

\section{Feedback Requirement 3: Interpretability and Intuitiveness}

Although the interpretability and intuitiveness of feedback are not described for prosthesis applications, they are influenced by both the perception of stimulus intensity and the perceived sensation and have been described in psychophysical studies.

The perceived stimulus intensity is strongly related to the applied stimulus intensity and best described by an (adjusted) power function [78-79], of which the exponent can vary greatly. For electrotactile stimulation, this is mainly due to the relationship between stimulus duration and stimulus intensity [80-81], and for vibrotactile stimulation, this depends on the position of stimulation [82]. The perceived stimulus intensity is influenced by the intensity, the duration and number of bursts of stimulation, the housing of the stimulator, the characteristics of the preceding stimulus, and the number of simultaneous stimuli [83].

The perceived sensations with vibrotactile stimulation are influenced by intensity, frequency and waveform of stimulation, actuator size, and location of stimulation. Therefore, they vary largely over the literature [82,84], from buzzing to sharp pain. Variations in perceived sensations with electrotactile stimuli are related to stimulus intensity, electrode characteristics, preparation of the skin, and the use of cathodic or anodic stimulation [81,85-86]. It was shown that sensations perceived by amputees do not differ from the sensations of nondisabled subjects for percutaneous stimulation [87].

\section{Feedback Requirement 4: User Comfort}

In the workshop, comfort was defined as a prosthesis not being obtrusive and not causing pain or skin problems. Therefore, auditory or optical feedback options were considered to be unsuitable for feedback in forearm prostheses. As mentioned previously, a major problem with feedback through electrical stimulation is the risk of generating painful sensations. This risk is influenced by the skin 
contacts, skin condition, type of stimulation (cathodic/ anodic), and the size of the electrode [85]. Alles showed that after 4 weeks of use, no adverse effects of vibrotactile stimulation on the skin occurred [88]. However, the effects of long-term vibrotactile or electrotactile stimulation are not addressed in the literature.

\section{Feedback Requirement 5: Adjustability of Location and Stimulus Intensity}

The ability to adjust the location or intensity of stimulation is influenced by the effects of the position of stimulation on the sensitivity, the subjective perception of position (localization), and the smallest detectable distance between stimulators (spatial acuity). The effects of the position of vibrotactile or electrotactile stimulation on all three aspects have been investigated in the literature, but their implications for prosthesis applications are not given.

At the glabrous skin, the sensitivity for vibrotactile stimulation is highest with its maximum for stimulations at $250 \mathrm{~Hz}$ (with a detection threshold of only several microns), but at the hairy skin, the sensitivity is lower and the maximum shifts to 200 to $220 \mathrm{~Hz}[82-83,89]$.

Localization performance is not only related to the position of stimulation, effects were also found for the space between the stimulators and the neighborhood of (bony) landmarks [90].

The spatial acuity highly depends on the stimulus position and can therefore vary greatly, from $2 \mathrm{~mm}$ to several centimeters [79]. For electrotactile stimulation, variations can also be caused by changes in frequency, pulse width, and pulse time delays [91]. Furthermore, temperature and stimulus type affect the spatial acuity for both types of stimulation [83,92].

An aspect that plays an important role in the adjustability of the stimulus intensity is adaptation, because if it occurs, the stimulus intensity should be adjusted to prevent fading. Adaptation can be reduced by changing the frequency of the subsequent stimulus or by applying the stimuli intermittently [83,93]. For electrotactile stimulation, adaptation is lowest for high current stimulation (just below the pain threshold) and can also be reduced by intermittent stimulation [94].

\section{DISCUSSION}

Functional requirements for user acceptance were determined in the "Needs Assessment Results" section, and the state of the art in ME forearm prosthesis research was reviewed according to these requirements in the "Literature Survey" section. Based on these studies, we can show to what degree recent research has been able to fulfill the acceptance requirements. In this section, the method used to perform the needs assessment is evaluated and the results of the literature review are discussed. For those requirements that are presently not completely fulfilled, recommendations for future research are made.

\section{Needs Assessment Evaluation}

The needs assessment devised for this article was set up in such a way that it would be generally applicable in future development of forearm prostheses. The workshop approach was well-structured, starting with selecting a number of relevant activities of daily living for forearm prosthesis users. The step-by-step worksheet (Figure 3) focused on the individual subtasks involved in each activity; this method was effective in pinpointing the specific needs associated with each activity. The workshop also encouraged communication between clinicians and engineers by having each activity investigated by small mixed subgroups. The therapists involved had firsthand experience with many different users, which gave them a broad perspective on the users' needs. However, for additional verification of the resulting requirements, we recommend reviewing them through questionnaires aimed at both users and professionals.

\section{Literature Discussion and Recommendations}

The discussions of the state of the art and recommendations for future research follow the structure of the requirements table (Table $\mathbf{1}$ ) and the literature survey.

\section{EMG Sensing}

The focus of recent research on ME prostheses has been on overcoming the major shortcoming of limited selectivity in control by increasing the number of controllable functions, which would ultimately lead to more efficient usage. As can be concluded from the overview of sensing systems in the literature (Table 2), classifiers that can distinguish multiple wrist movements with good accuracy are widely available. However, these results may be skewed because many studies are performed using nondisabled subjects and a number of restraints in the contractions. Moreover, these classifier systems are not used in commercially available prostheses. With regard to grasps, far fewer results are found. A requirement resulting from the workshop was 
not only to include more functions in forearm prostheses but also to accommodate more practical functions, such as grasps to manipulate and maneuver different types of objects. The functions of the prosthesis should match the contraction patterns the user has to make as much as possible (direct mapping) to enable natural and intuitive control. Therefore, to completely fulfill the first EMG sensing requirement, the following is required: a thorough validation with amputee patients and a real-time experimental setup of a pattern-recognition system that is also able to distinguish grasp patterns.

Concerning the nondisturbing time delay requirement, most studies keep within the 300 ms boundary of perceived user delay, as can be seen in Table 2 . The possibility of achieving acceptable accuracies with analysis windows under 125 ms needs to be investigated. It should be noted that the clinical relevance of higher accuracies is hard to determine, as it is unknown what degree of accuracy is satisfactory for actual use. Among other things, performance depends on the activity performed and the objects involved, and these influences need to be further investigated.

To reiterate, the prosthesis control should resemble the original neuromuscular control as much as possible to make it natural and intuitive. Therefore, an ideal sensing system should enable user control of force, speed, or both, as well as simultaneous control of multiple movements. However, the requirements on proportional and simultaneous control are rarely covered in the literature; future research in this area is therefore recommended.

\section{Control}

In order to ensure user acceptance of a new ME prosthesis, both the control system and the mechanical design would need to accommodate several new features and an elegant way of controlling these features.

The prosthesis prototypes featuring discrete grasp types are capable of performing most, if not all, of the required grasps. However, the relative absence of wrist movements beyond occasional rotation needs to be addressed. If wrist rotation or flexion/extension is made available, we recommend including simultaneous control of wrist movement and grasp selection. The degree of automation in the reviewed systems is also important; it can reduce the control required from the user but may also be considered unintuitive. A good example of a feature that greatly benefits from automation is the holding of a grasped object, which is implemented in several of the reviewed systems $[52,54,59,73]$. Since it allows the user to focus their attention on using the object they are holding, we recommended this feature be included in any user-friendly system. An extension of this concept is active force control by the prosthesis, which is application of just enough pressure to prevent slipping. This function, though less common [54], can allow a much wider range of objects to be easily handled; however, fragile or flexible objects could prove difficult to manage.

The average grasp execution time among the reviewed prototypes is still quite high (Table 3). Decreasing this time is recommended in order to increase the prosthesis' responsiveness and dynamic appearance as well as making direct speed control more useful. Improving the prosthesis' speed can be accomplished by using faster actuators, such as the hydraulic actuators of the Fluidhand [73], or the various types of pneumatic actuators available [95].

User force control should be available for when automatic holding and slip prevention are unwanted or impractical. However, because of the inevitable delays and inaccuracies in the feedback loop between the prosthesis and the user, maintaining precise control over the applied force can be difficult. Instead, an approach such as used on the Southampton hand [54], providing optional force control when an object is being held, would be preferable.

\section{Feedback}

Feedback of force and position is only marginally addressed in research applications. The use of direct nerve stimulation and EPT seem to have a high potential to circumvent differences in modalities between sensing and stimulation. However, pressure systems as used in EPT are highly sensitive to adaptation and the application of direct nerve stimulation is still in a very experimental stage. More applications were found for electrotactile stimulation, but the sensations evoked by it can be painful and unfamiliar to the user, likely because of the various kinds of mechanoreceptors that are activated simultaneously [96]. For this reason, the recent focus is mainly on vibrotactile stimulation, which has great potential because it is relatively unobtrusive to the user and the environment and, therefore, fulfills the comfort requirement. However, the developed methods should be investigated on a larger scale as well as on amputee patients.

No distinction is made between continuous and discrete feedback in the literature. In almost every case, proportional feedback is presented by amplitude or frequency modulation in a linear or nonlinear way. Future focus should be on the determination of the optimal modulation techniques for feedback applications. 
Research on interpretability, intuitiveness, and adjustability is mainly focused on psychophysical experiments and described extensively. However, the right way to implement the findings from these studies in a successful forearm prosthesis still has to be investigated. Furthermore, the applicability for amputee patients and any comfort issues are hardly described and should be investigated in future research.

\section{CONCLUSIONS}

Recent developments in ME forearm prosthesis research are mainly technology driven, doing little to increase the low user acceptance rates. In this study, a user-centered approach is used to derive the requirements for a natural and intuitive prosthesis.

One of the main requirements is the application of force and position feedback, which is rarely implemented in recent prototype prostheses. The focus of future research should therefore be on the implementation of these kinds of feedback, whereby the extensively investigated psychophysical aspects should be taken into account.

Recent research in grasp selection and control is promising, fulfilling most of the associated requirements. However, simultaneous control of grasps and wrist movements should be implemented to increase the natural motion and intuitiveness of grasping maneuvers.

The automation of object holding and slip prevention can reduce the required attention during bimanual tasks. The implementation of this feature in future prostheses was recommended in the needs assessment.

The long reaction time of many modern prostheses was noted, which decreases the intuitiveness of their control. In EMG sensing, reducing the time window for classification while maintaining sufficient accuracy is being investigated. Similarly, the grasp execution time is still significantly impaired, mainly because of the use of DC motors. Research into alternative actuation is therefore highly recommended.

Although many of the required components for a natural and intuitive prosthesis system are currently available or being developed, more attention needs to be paid toward their integration and validation by a large group of users. Hopefully, these user-centered requirements and recommendations will increase acceptance of the next generation of ME forearm prostheses.

\section{ACKNOWLEDGMENTS}

\section{Author Contributions:}

Drafting of manuscript: B. Peerdeman.

Workshop organization: R. Huis in 't Veld.

Literature review: B. Peerdeman, D. Boere, H. Witteveen.

Critical revision of manuscript for important intellectual content:

S. Misra, P. Veltink, H. Rietman, H. Hermens, S. Stramigioli.

Financial Disclosures: The authors have declared that no competing interests exist.

Funding/Support: This material (project Myopro: http://www.myopro.nl) was based on work supported by the Dutch Ministry of Economic Affairs and the Province of Overijssel, within the Pieken in de Delta (PIDON) initiative. All authors are affiliated with MIRA-Institute for Biomedical Technology and Technical Medicine, University of Twente.

Additional Contributions: We would like to acknowledge the support of Laura Kallenberg for organizing the workshop and useful discussions that led to this research. The contributions of all participants in the workshop are greatly appreciated.

\section{REFERENCES}

1. Atkins DJ, Heard DC, Donovan WH. Epidemiologic overview of individuals with upper-limb loss and their reported research priorities. J Prosthet Orthot. 1996;8(1):2-11. DOI:10.1097/00008526-199600810-00003

2. Biddiss E, Chau T. Upper-limb prosthetics: Critical factors in device abandonment. Am J Phys Med Rehabil. 2007; 86(12):977-87. [PMID: 18090439] DOI:10.1097/PHM.0b013e3181587f6c

3. Pons JL, Ceres R, Rocon E, Reynaerts D, Saro B, Levin S, Van Moorleghem W. Objectives and technological approach to the development of the multifunctional MANUS upper limb prosthesis. Robotica. 2005;23(3):301-10. DOI:10.1017/S0263574704001328

4. The i-LIMB Hand [Internet]. Hilliard $(\mathrm{OH})$ : Touch Bionics; 2011. Available from: http://www.touchbionics.com/i-LIMB.

5. Bebionic [Internet]. Leeds (UK): RSL Steeper; 2011. Available from: http://www.bebionic.com/.

6. Michelangelo hand [Internet]. Duderstadt (Germany): Otto Bock; 2011. Available from: http://www.ottobock.com/.

7. Klopsteg PE, Wilson PD. Human limbs and their substitutes. New York (NY): Hafner; 1954.

8. Huis in 't Veld RM, Widya IA, Bults RG, Sandsjö L, Hermens HJ, Vollenbroek-Hutten MM. A scenario guideline for designing new teletreatments: A multidisciplinary approach. J Telemed Telecare. 2010;16(6):302-7. [PMID: 20798423] DOI:10.1258/jtt.2010.006003

9. Beynon-Davies P, Holmes S. Design breakdowns, scenarios and rapid application development. Inform Software Technol. 2002;44(10):579-92. DOI:10.1016/S0950-5849(02)00078-2 
10. Bookman A, Harrington M, Pass L, Reisner E. Family caregiver handbook. Cambridge (MA): Massachusetts Institute of Technology; 2007.

11. Biddiss EA, Chau TT. Upper limb prosthesis use and abandonment: A survey of the last 25 years. Prosthet Orthot Int. 2007;31(3):236-57. [PMID: 17979010]

DOI:10.1080/03093640600994581

12. Hermens HJ. Surface EMG. Enschede (the Netherlands): Febodruk; 1991.

13. Su Y, Wolczowski A, Fisher MH, Bell GD, Burn D, Gao R. Towards an EMG controlled prosthetic hand using a 3D electromagnetic positioning system. Proceedings of the IEEE Instrumentation and Measurement Technology Conference; 2005 May 16-19; Ottawa, Canada. Los Alamitos (CA): IEEE; 2005. p. 261-66. DOI:10.1109/IMTC.2005.1604113

14. De Luca C. Electromyography. In: Webster JG, editor. Encyclopedia of medical devices and instrumentation. Boston (MA): John Wiley \& Sons; 2006. p. 98-109.

DOI:10.1002/0471732877.emd097

15. Asghari Oskoei M, Hu H. Myoelectric control systems-A survey. Biomed Signal Process Control. 2007;2(4):275-94.

16. Zecca M, Micera S, Carrozza MC, Dario P. Control of multifunctional prosthetic hands by processing the electromyographic signal. Crit Rev Biomed Eng. 2002;30(4-6):459-85. [PMID: 12739757]

DOI:10.1615/CritRevBiomedEng.v30.i456.80

17. Hudgins B, Parker P, Scott RN. A new strategy for multifunction myoelectric control. IEEE Trans Biomed Eng. 1993; 40(1):82-94. [PMID: 8468080]

DOI:10.1109/10.204774

18. Merletti R, Parker P. Electromyography: Physiology, engineering, and noninvasive applications. Hoboken (NJ): John Wiley \& Sons; 2004. DOI:10.1002/0471678384

19. Englehart K, Hudgins B. A robust, real-time control scheme for multifunction myoelectric control. IEEE Trans Biomed Eng. 2003;50(7):848-54. [PMID: 12848352] DOI:10.1109/TBME.2003.813539

20. Ajiboye AB, Weir RF. A heuristic fuzzy logic approach to EMG pattern recognition for multifunctional prosthesis control. IEEE Trans Neural Syst Rehabil Eng. 2005;13(3): 280-91. [PMID: 16200752]

DOI:10.1109/TNSRE.2005.847357

21. Sebelius F, Axelsson M, Danielsen N, Schouenborg J, Laurell T. Real-time control of a virtual hand. Technol Disabil. 2005;17(3):131-41.

22. Hargrove L, Losier Y, Lock B, Englehart K, Hudgins B. A real-time pattern recognition based myoelectric control usability study implemented in a virtual environment. Conf Proc IEEE Eng Med Biol Soc. 2007;2007:4842-45. [PMID: 18003090]

23. Asghari Oskoei M, Hu H. Evaluation of support vector machines in upper limb motion classification using myoelec- tric signal. Proceedings of the Iranian Conference on Biomedical Engineering; 2008; Shahed University, Iran. p. 176-80.

24. Shenoy P, Miller KJ, Crawford B, Rao RN. Online electromyographic control of a robotic prosthesis. IEEE Trans Biomed Eng. 2008;55(3):1128-35. [PMID: 18334405] DOI:10.1109/TBME.2007.909536

25. Englehart K, Hudgins B, Parker PA. A wavelet-based continuous classification scheme for multifunction myoelectric control. IEEE Trans Biomed Eng. 2001;48(3):302-11. [PMID: 11327498]

DOI:10.1109/10.914793

26. Farrell TR, Weir RF. Pilot comparison of surface vs. implanted EMG for multifunctional prosthesis control. In: Proceedings of the IEEE 9th International Conference on Rehabilitation Robotics (ICORR); 2005 Jun 28-Jul 1; Chicago, IL. Los Alamitos (CA): IEEE; 2005. p. 277-80. DOI:10.1109/ICORR.2005.1501101

27. Tenore F, Armiger RS, Vogelstein RJ, Wenstrand DS, Harshbarger SD, Englehart K. An embedded controller for a 7-degree of freedom prosthetic arm. Conf Proc IEEE Eng Med Biol Soc. 2008;2008:185-88. [PMID: 19162624]

28. Sensinger JW, Lock BA, Kuiken TA. Adaptive pattern recognition of myoelectric signals: Exploration of conceptual framework and practical algorithms. IEEE Trans Neural Syst Rehabil Eng. 2009;17(3):270-78. [PMID: 19497834] DOI:10.1109/TNSRE.2009.2023282

29. Sebelius FC, Rosén BN, Lundborg GN. Refined myoelectric control in below-elbow amputees using artificial neural networks and a data glove. J Hand Surg Am. 2005;30(4): 780-89. [PMID: 16039372] DOI:10.1016/j.jhsa.2005.01.002

30. León M, Leija L, Munoz R. System for the identification of multiple movements of the hand. Proceedings of the 3rd International Conference on Electrical and Electronics Engineering; 2006 Sep 6-8; Veracruz, Mexico. Los Alamitos (CA): IEEE; 2006. p. 1-3.

31. Arvetti M, Gini G, Folgheraiter M. Classification of EMG signals through wavelet analysis and neural networks for controlling an active hand prosthesis. Proceedings of the IEEE 10th International Conference on Rehabilitation Robotics; 2007 Jun 13-15; Noordwijk, the Netherlands. Los Alamitos (CA): IEEE; 2007. p. 531-36. DOI:10.1109/ICORR.2007.4428476

32. Ito K, Tsuji T, Kato A, Ito M. Limb-function discrimination using EMG signals by neural network and application to prosthetic forearm control. Proceedings of the IEEE International Joint Conference on Neural Networks; 1991 Nov 1821; Singapore. Los Alamitos (CA): IEEE; 1991. p. 1214-19. DOI:10.1109/IJCNN.1991.170562

33. Kuruganti U, Daley H, Englehart KB. High density EMG data of normally limbed and transradial amputees. Proceedings of the Congress of the International Society of Electrophysiology and Kinesiology (ISEK); 2010 Jun 16-19; Aalborg, Denmark. 
34. Zhou R, Liu X, Li G. Myoelectric signal feature performance in classifying motion classes in transradial amputees. Proceedings of the Congress of the International Society of Electrophysiology and Kinesiology (ISEK). 2010 Jun 16-19; Aalborg, Denmark.

35. Tenore FV, Ramos A, Fahmy A, Acharya S, EtienneCummings R, Thakor NV. Decoding of individuated finger movements using surface electromyography. IEEE Trans Biomed Eng. 2009;56(5):1427-34. [PMID: 19473933] DOI:10.1109/TBME.2008.2005485

36. Hargrove LJ, Englehart K, Hudgins B. A comparison of surface and intramuscular myoelectric signal classification. IEEE Trans Biomed Eng. 2007;54(5):847-53. [PMID: 17518281] DOI:10.1109/TBME.2006.889192

37. Khezri M, Jahed M. Real-time intelligent pattern recognition algorithm for surface EMG signals. Biomed Eng Online. 2007;6:45. [PMID: 18053184]

DOI:10.1186/1475-925X-6-45

38. Khushaba RN, Al-Jumaily A. Channel and feature selection in multifunction myoelectric control. Conf Proc IEEE Eng Med Biol Soc. 2007;2007:5182-25. [PMID: 18003175]

39. Farrell TR, Weir RF. The optimal controller delay for myoelectric prostheses. IEEE Trans Neural Syst Rehabil Eng. 2007;15(1):111-18. [PMID: 17436883]

DOI:10.1109/TNSRE.2007.891391

40. Hargrove LJ, Scheme EJ, Englehart KB, Hudgins BS. Multiple binary classifications via linear discriminant analysis for improved controllability of a powered prosthesis. IEEE Trans Neural Syst Rehabil Eng. 2010;18(1):49-57.

[PMID: 20071277] DOI:10.1109/TNSRE.2009.2039590

41. Li G, Schultz AE, Kuiken TA. Quantifying pattern recognition-based myoelectric control of multifunctional transradial prostheses. IEEE Trans Neural Syst Rehabil Eng. 2010; 18(2):185-92. [PMID: 20071269]

42. Yang DP, Zhao JD, Jiang L, Liu H. Study on recognition of multi-mode hand gestures based on myoelectric signal. J Shanghai Jiaotong University. 2009;43(7):1701-5.

43. Smith RJ, Tenore F, Huberdeau D, Etienne-Cummings R, Thakor NV. Continuous decoding of finger position from surface EMG signals for the control of powered prostheses. Conf Proc IEEE Eng Med Biol Soc. 2008;2008:197-200. [PMID: 19162627$]$

44. De Luca CJ. Surface electromyography: Detection and recording. Boston (MA): DelSys Inc; 2002.

45. Staudenmann D, Kingma I, Daffertshofer A, Stegeman DF, Van Dieën JH. Improving EMG-based muscle force estimation by using a high-density EMG grid and principal component analysis. IEEE Trans Biomed Eng. 2006;53(4): 712-19. [PMID: 16602578]

DOI:10.1109/TBME.2006.870246

46. Hargrove L, Zhou P, Englehart K, Kuiken TA. The effect of ECG interference on pattern-recognition-based myoelectric control for targeted muscle reinnervated patients. IEEE Trans Biomed Eng. 2009;56(9):2197-2201. [PMID: 19692302] DOI:10.1109/TBME.2008.2010392

47. Jiang N, Englehart KB, Parker PA. Extracting simultaneous and proportional neural control information for multiple-DOF prostheses from the surface electromyographic signal. IEEE Trans Biomed Eng. 2009;56(4):1070-80. [PMID: 19272889] DOI:10.1109/TBME.2008.2007967

48. Nielsen JL, Holmgaard S, Jiang N, Englehart K, Farina D, Parker P. Enhanced EMG signal processing for simultaneous and proportional myoelectric control. Conf Proc IEEE Eng Med Biol Soc. 2009;2009:4335-38. [PMID: 19963822]

49. Muceli S, Jiang N, Farina D. Simultaneous and proportional estimation of multiple degrees of freedom in hand kinematics from the surface EMG. Proceedings of the Congress of the International Society of Electrophysiology and Kinesiology (ISEK); 2010 Jun 16-19; Aalborg, Denmark.

50. Herberts P, Almström C, Kadefors R, Lawrence PD. Hand prosthesis control via myoelectric patterns. Acta Orthop Scand. 1973;44(4):389-409. [PMID: 4771275]

51. Siciliano B, Khatib O, editors. Springer handbook of robotics. Berlin (Germany): Springer; 2008.

52. Pons JL, Ceres R, Rocon E, Levin S, Markovitz I, Saro B, Reynaerts D, Van Moorleghem W, Bueno L. Virtual reality training and EMG control of the MANUS hand prosthesis. Robotica. 2005;23(3):311-17. DOI:10.1017/S026357470400133X

53. Schulz S, Pylatiuk C, Reischl M, Martin J, Mikut R, Bretthauer G. A hydraulically driven multifunctional prosthetic hand. Robotica. 2005;23(3):293-99. DOI:10.1017/S0263574704001316

54. Light CM, Chappell PH, Hudgins B, Engelhart K. Intelligent multifunction myoelectric control of hand prosthesis. J Med Eng Technol. 2002;26(4):139-46. [PMID: 12396328] DOI:10.1080/03091900210142459

55. Yang DP, Zhao JD, Gu YK, Wang XQ, Li N, Jiang L, Liu $\mathrm{H}$, Huang $\mathrm{H}$, Zhao DW. An anthropomorphic robot hand developed based on underactuated mechanism and controlled by EMG signals. J Bionic Eng. 2009;6(3):255-63. DOI:10.1016/S1672-6529(08)60119-5

56. Matrone G, Cipriani C, Secco EL, Carrozza MC, Magenes G. Bio-inspired controller for a dexterous prosthetic hand based on principal components analysis. Conf Proc IEEE Eng Med Biol Soc. 2009;2009:5022-25. [PMID: 19964659]

57. Cipriani C, Zaccone F, Micera S, Carrozza MC. On the shared control of an EMG-controlled prosthetic hand: Analysis of user-prosthesis interaction. IEEE Trans Robotics. 2008; 24(1):170-84. DOI:10.1109/TRO.2007.910708

58. Pons JL, Rocon E, Ceres R, Reynaerts D, Saro B, Levin S, Van Moorleghem W. The MANUS-HAND dextrous robotics upper limb prosthesis: Mechanical and manipulation aspects. Autonomous Robots. 2004;16(2):143-63. DOI:10.1023/B:AURO.0000016862.38337.f1 
59. Carrozza MC, Cappiello G, Micera S, Edin BB, Beccai L, Cipriani C. Design of a cybernetic hand for perception and action. Biol Cybern. 2006;95(6):629-44. [PMID: 17149592] DOI:10.1007/s00422-006-0124-2

60. Simpson DC. The choice of control system for the multimovement prosthesis: Extended physiological proprioception. In: Herberts P, editor. The control of upper-extremity prostheses and orthoses. Springfield (IL): Thomas; 1974. p. 146-50.

61. Dhillon GS, Horch KW. Direct neural sensory feedback and control of a prosthetic arm. IEEE Trans Neural Syst Rehabil Eng. 2005;13(4):468-72. [PMID: 16425828] DOI:10.1109/TNSRE.2005.856072

62. Di Pino G, Guglielmelli E, Rossini PM. Neuroplasticity in amputees: Main implications on bidirectional interfacing of cybernetic hand prostheses. Prog Neurobiol. 2009;88(2): 114-26. [PMID: 19482228] DOI:10.1016/j.pneurobio.2009.03.001

63. Gasson M, Hutt B, Goodhew I, Kyberd PJ, Warwick K. Invasive neural prosthesis for neural signal detection and nerve stimulation. Int J Adapt Control. 2005;19(5):365-75.

64. Fan RE, Culjat MO, King CH, Franco ML, Boryk R, Bisley JW, Dutson E, Grundfest WS. A haptic feedback system for lower-limb prostheses. IEEE Trans Neural Syst Rehabil Eng. 2008;16(3):270-77. [PMID: 18586606]

DOI:10.1109/TNSRE.2008.920075

65. Meek SG, Jacobsen SC, Goulding PP. Extended physiologic taction: Design and evaluation of a proportional force feedback system. J Rehabil Res Dev. 1989;26(3):53-62. [PMID: 2666644]

66. Patterson PE, Katz JA. Design and evaluation of a sensory feedback system that provides grasping pressure in a myoelectric hand. J Rehabil Res Dev. 1992;29(1):1-8.

[PMID: 1740774]

DOI:10.1682/JRRD.1992.01.0001

67. Beeker TW, During J, Den Hertog A. Artificial touch in a hand-prosthesis. Med Biol Eng. 1967;5(1):47-49.

[PMID: 6037625]

DOI:10.1007/BF02478841

68. Rohland TA. Sensory feedback for powered limb prostheses. Med Biol Eng. 1975;13(2):300-1. [PMID: 1195823]

DOI:10.1007/BF02477743

69. Schmidl H. The importance of information feedback in prostheses for the upper limbs. Prosthet Orthot Int. 1977; 1(1):21-24. [PMID: 615983]

70. Scott RN, Brittain RH, Caldwell RR, Cameron AB, Dunfield VA. Sensory-feedback system compatible with myoelectric control. Med Biol Eng Comput. 1980;18(1):65-69. [PMID: 7382591] DOI:10.1007/BF02442481

71. Shannon GF. A myoelectrically-controlled prosthesis with sensory feedback. Med Biol Eng Comput. 1979;17(1):73-80.
[PMID: 312386]

DOI:10.1007/BF02440956

72. Wang G, Zhang X, Zhang J, Gruver WA. Gripping force sensory feedback for a myoelectrically controlled forearm prosthesis. Proceedings of the IEEE International Conference on Systems, Man and Cybernetics; 1995 Oct 22-25; Vancouver, Canada. Los Alamitos (CA): IEEE; 1995. p. 501-4.

73. Pylatiuk C, Mounier S, Kargov A, Schulz S, Bretthauer G. Progress in the development of a multifunctional hand prosthesis. Conf Proc IEEE Eng Med Biol Soc. 2004;6: 4260-63. [PMID: 17271245]

74. Pylatiuk C, Kargov A, Schulz S. Design and evaluation of a low-cost force feedback system for myoelectric prosthetic hands. J Prosthet Orthot. 2006;18(2):57-61. DOI:10.1097/00008526-200604000-00007

75. Prior RE, Lyman J. Electrocutaneous feedback for artificial limbs. Summary progress report. February 1, 1974, through July 31, 1975. Bull Prosthet Res. 1975;10(24):3-37. [PMID: 1227686]

76. Prior RE, Lyman J, Case PA, Scott CM. Supplemental sensory feedback for the VA/NU myoelectric hand. Background and preliminary designs. Bull Prosthet Res. 1976; 10(25):170-91. [PMID: 1030327]

77. Mann RW, Reimers SD. Kinesthetic sensing for the EMG controlled “Boston Arm.” IEEE Trans Man Machine Syst. 1970;11(1):110-15. DOI:10.1109/TMMS.1970.299971

78. Kandel ER, Schwartz JH, Jessell TM. Principles of neural science. 4th ed. New York (NY): McGraw-Hill; 2000.

79. Marcus PL, Fuglevand AJ. Perception of electrical and mechanical stimulation of the skin: Implications for electrotactile feedback. J Neural Eng. 2009;6(6):066008.

[PMID: 19918109] DOI:10.1088/1741-2560/6/6/066008

80. Babkoff H. Electrocutaneous psychophysical input-output functions and temporal integration. Percept Psychophys. 1978;23(3):251-57. [PMID: 662576] DOI:10.3758/BF03204134

81. Tashiro T, Higashiyama A. The perceptual properties of electrocutaneous stimulation: Sensory quality, subjective intensity, and intensity-duration relation. Percept Psychophys. 1981;30(6):579-86. [PMID: 7335455] DOI:10.3758/BF03202013

82. Jones LA, Sarter NB. Tactile displays: Guidance for their design and application. Human Factors. 2008;50(1):90-111. [PMID: 18354974] DOI:10.1518/001872008X250638

83. Cheung B, Van Erp JB, Cholewiak RW. Anatomical, neurophysiological and perceptual issues of tactile perception. In: Van Erp JB, Self BP, editors. Tactile displays for orientation, navigation and communication in air, sea and land environments. Neuilly-sur-Sein Cedex (France): NATO Research and Technology Organisation; 2008. p. 1-18. 
PEERDEMAN et al. Myoelectric forearm prostheses

84. Sherrick CE, Cholewiak RW, Collins AA. The localization of low- and high-frequency vibrotactile stimuli. J Acoust Soc Am. 1990;88(1):169-79. [PMID: 2380445]

DOI:10.1121/1.399937

85. Kaczmarek KA, Kramer KM, Webster JG, Radwin RG. A 16-channel 8-parameter waveform electrotactile stimulation system. IEEE Trans Biomed Eng. 1991;38(10):933-43.

[PMID: 1761295]

DOI:10.1109/10.88439

86. Pfeiffer EA. Electrical stimulation of sensory nerves with skin electrodes for research, diagnosis, communication and behavioral conditioning: A survey. Med Biol Eng. 1968; 6(6):637-51. [PMID: 4891827] DOI:10.1007/BF02474726

87. Anani A, Körner L. Discrimination of phantom hand sensations elicited by afferent electrical nerve stimulation in belowelbow amputees. Med Prog Technol. 1979;6(3):131-35. [PMID: 481362]

88. Alles DS. Information transmission by phantom sensations. IEEE Trans Man Machine Syst. 1970;11(1):85-91. DOI:10.1109/TMMS.1970.299967

89. Mahns DA, Perkins NM, Sahai V, Robinson L, Rowe MJ. Vibrotactile frequency discrimination in human hairy skin. J Neurophysiol. 2006;95(3):1442-50. [PMID: 16319219] DOI:10.1152/jn.00483.2005

90. Cholewiak RW, Collins AA. Vibrotactile localization on the arm: Effects of place, space, and age. Percept Psychophys. 2003;65(7):1058-77. [PMID: 14674633] DOI:10.3758/BF03194834

91. Solomonow M, Lyman J, Freedy A. Electrotactile two-point discrimination as a function of frequency, body site, laterality, and stimulation codes. Ann Biomed Eng. 1977;5(1):47-60. [PMID: 851263]

92. Mortimer BJ, Zets GA, Cholewiak RW. Vibrotactile transduction and transducers. J Acoust Soc Am. 2007;121(5):
2970-77. [PMID: 17550194$]$

DOI:10.1121/1.2715669

93. Shannon GF. A comparison of alternative means of providing sensory feedback on upper limb prostheses. Med Biol Eng. 1976;14(3):289-94. [PMID: 940388] DOI:10.1007/BF02478123

94. Buma DG, Buitenweg JR, Veltink PH. Intermittent stimulation delays adaptation to electrocutaneous sensory feedback. IEEE Trans Neural Syst Rehabil Eng. 2007;15(3): 435-41. [PMID: 17894276] DOI:10.1109/TNSRE.2007.903942

95. Plettenburg DH. Electric versus pneumatic power in hand prostheses for children. J Med Eng Technol. 1989;13(1-2): 124-28. [PMID: 2733004 DOI:10.3109/03091908909030211

96. Kaczmarek KA, Webster JG, Bach-y-Rita P, Tompkins WJ. Electrotactile and vibrotactile displays for sensory substitution systems. IEEE Trans Biomed Eng. 1991;38(1):1-16. [PMID: 2026426] DOI:10.1109/10.68204

Submitted for publication August 27, 2010. Accepted in revised form April 5, 2011.

This article and any supplementary material should be cited as follows:

Peerdeman B, Boere D, Witteveen H, Huis in 't Veld R, Hermens H, Stramigioli S, Rietman H, Veltink P, Misra S. Myoelectric forearm prostheses: State of the art from a user-centered perspective. J Rehabil Res Dev. 2011;48(6): 719-38.

DOI:10.1682/JRRD.2010.08.0161

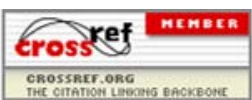


